\title{
The Use of Antiepileptic Drugs in Acute Neuropsychiatric Conditions: Focus on Traumatic Brain Injury, Pain, and Alcohol Withdrawal
}

\author{
Shamim H. Nejad ${ }^{*}$, Kathy Chuang2, Ronald Hirschberg3, Patrick R. Aquino4, \\ Gregory L. Fricchione ${ }^{1}$ \\ ${ }^{1}$ Division of Psychiatry and Medicine, Massachusetts General Hospital, \\ Boston, MA, USA \\ ${ }^{2}$ Department of Neurology, Massachusetts General Hospital, Boston, MA, USA \\ ${ }^{3}$ Department of Physical Medicine and Rehabilitation, Spaulding Rehabilitation Hospital, \\ Massachusetts General Hospital, Boston, MA, USA \\ ${ }^{4}$ Department of Psychiatry, Lahey Medical Center, Burlington, MA, USA \\ Email: snejad@mgh.harvard.edu
}

Received 12 April 2014; revised 11 May 2014; accepted 10 June 2014

Copyright (C) 2014 by authors and Scientific Research Publishing Inc.

This work is licensed under the Creative Commons Attribution International License (CC BY). http://creativecommons.org/licenses/by/4.0/

(c) (i) Open Access

\begin{abstract}
Antiepileptic drugs (AEDs), have demonstrated efficacy treating a number of acute conditions, encompassing a broad range of symptoms and syndromes, in addition to being first-line treatment for epilepsy. Clinically, since their inception, AEDs have been used off-label for acute and chronic medical conditions, both as primary and as adjuvant therapies. In this review, we describe the observed clinical effectiveness of AEDs across a set of commonly encountered acute conditions in the general hospital: traumatic brain injury, pain, alcohol withdrawal. In describing the individual benefits and usages of specific agents, the applicability of these agents to other common neuropsychiatric conditions may be further explored.
\end{abstract}

\section{Keywords}

Antiepileptic Drugs, Traumatic Brain Injury, Alcohol Withdrawal, Pain, Valproic Acid, Carbamazepine

\footnotetext{
${ }^{*}$ Corresponding author.
}

How to cite this paper: Nejad, S.H., Chuang, K., Hirschberg, R., Aquino, P.R. and Fricchione G.L. (2014) The Use of Antiepileptic Drugs in Acute Neuropsychiatric Conditions: Focus on Traumatic Brain Injury, Pain, and Alcohol Withdrawal. International Journal of Clinical Medicine, 5, 724-736. http://dx.doi.org/10.4236/ijcm.2014.512099 


\section{Introduction}

Treatment in the general hospital focuses on acute care of patients with a variety of conditions from the straightforward to the complex. Antiepileptic drugs (AEDs), have demonstrated efficacy treating a number of acute conditions, encompassing a broad range of symptoms and syndromes, and remain the mainstay of first-line treatment for epilepsy [1]. Since their development, there has been an expanding role for AEDs in treating a variety of conditions including pain syndromes, sequelae of traumatic brain injury, delirium, and alcohol withdrawal, among others.

Antiepileptic medications can be traced back to the bromides of the $19^{\text {th }}$ century, which then gave way to phenobarbital of the early- $20^{\text {th }}$ century. Phenytoin emerged in the mid-20 ${ }^{\text {th }}$ century and has remained the firstline treatment of epilepsy [2]. Subsequent years have seen the development of newer agents each with varying mechanisms of action, changing side-effect profiles and less toxicity. Despite their unique mechanisms of action, the ultimate role remains the same: to diminish or suppress neuronal activity or reactivity. This neuronal suppression is accomplished through sodium channel blockade, calcium channel inhibition, gamma-aminobutyric acid (GABA) enhancement, glutamate blockade, carbonic anhydrase inhibition and other unknown mechanisms [3].

One hundred years after their development, in the US, AEDs have indications in the treatment of epilepsy, migraine, bipolar disorder, chronic pain, trigeminal neuralgia and fibromyalgia [4]. Clinically, since their inception, AEDs have been used off-label for acute and chronic conditions both as primary and as adjuvant therapies. Patients' presentations of illness in the general hospital are infused with a broad spectrum of neuropsychiatric symptoms. As a class of medications, AEDs effect changes in behavior, affect, and cognition as positive effects or side effects. Affectively these medications are utilized to target irritability, distractibility, anxiety or mood stability. Behavioral syndrome targets include seizure, impulsivity, restlessness or agitation. Cognitively, these medications are noted to have side effects of cognitive dulling, sedation, or slowed thinking. Considering traumatic brain injury as an example of a syndrome complicated by seizure, pain, spasticity, agitation, or other neurobehavioral changes, the use of AEDs with multiple applications becomes apparent.

In this review, we describe the observed clinical effectiveness of AEDs across a set of commonly encountered acute conditions in the general hospital: traumatic brain injury (TBI), pain, alcohol withdrawal. In describing the individual benefits and usages of specific agents, we hope to expand the applicability of these agents to other common neuropsychiatric conditions.

\section{Antiepileptic Drugs for the Treatment of Acute Traumatic Brain Injury}

Traumatic brain injury (TBI) impacts a significant proportion of Americans, accounting for 1.1 million emergency department visits per year and leading to approximately $2 \%$ of the U.S. population requiring long-term help to perform activities of daily living [5]. Patients with traumatic brain injury are most often prescribed AEDs for post-traumatic seizures, neurobehavioral disorders, and pain. Up to 26\% of TBI patients are prescribed these medications chronically after injury, and AEDs are the most frequently prescribed medications in TBI patients under the age of 65 [6].

Clinical evidence demonstrates efficacy of AEDs in attenuation of agitation and frontal lobe dysfunction following TBI during the period of acute hospitalization [7] [8]. Clinical experience has also shown that these agents may be helpful alternatives to more classically sedating medications such as dopamine antagonists, benzodiazepines or opiate medications. The following is a brief review of the use of AEDs for seizure and agitation associated with TBI.

\subsection{AEDs and Post-Traumatic Seizures}

Traumatic brain injury causes approximately 30\% of new-onset seizures in patients between 15 - 34 years of age and accounts for $6 \%$ of seizures in all age groups [9]. Post-traumatic seizures are defined by the time period after injury: 1) Immediate seizures occur $<24$ hrs after injury, 2) Early seizures occur $>24$ hrs and $<1$ week after injury, and 3) Late seizures (a.k.a. post-traumatic epilepsy) occur $>1$ week after injury. Risk factors for developing early seizures include: intracerebral hemorrhage, younger age, alcoholism, and increasing severity of injury [10]. Major risk factors for developing late seizures include: Increasing severity of TBI, skull fracture, intracranial hematoma (especially subdural hematoma), dural penetration with bone or metal fragments, depressed 
consciousness at time of initial presentation, brain contusions, and the development of early seizures [11]. Thus, the prevention of early seizures could serve to reduce risk of late seizures in TBI.

In adult patients with severe TBI, a recent Cochrane Review recommended initiating prophylactic treatment with phenytoin as soon as possible after injury to decrease the risk of post-traumatic seizures occurring within the first seven days from injury [9]. It is estimated that for every 100 patients treated, 10 patients would be kept seizure free within the first week. There was no associated decrease in mortality, neurological disability or late post-traumatic seizures [12]. Data are inconclusive with regard to ongoing prophylactic treatment with phenytoin, carbamazepine, or valproate (VPA) beyond the first seven days after injury to decrease the risk of posttraumatic seizures [9]. Levetiracetam has been used with increasing frequency due to ease of dosing and its role in post-traumatic seizures is still being defined. One trial comparing the effectiveness of levetiracetam versus phenytoin demonstrated no significant difference between the two medications, although there were increased abnormal findings on EEG compared to phenytoin [6] [13].

\subsection{AEDs for Agitation Following Acute Traumatic Brain Injury}

As demonstrated by a survey of TBI experts in 1997, "agitation" is a commonly used, yet poorly defined, term [14]. Defined in the Oxford-English dictionary as "a state of anxiety; nervous excitement", it has different connotations in the brain injury population [15]. Clinically, agitation has been classically perceived as increased psychomotor movements that may lead to injury to or abuse to equipment, caretakers, patients or others. Agitation rarely has a single etiology, but rather is a compilation of multitude of factors, including confusion, pain, medications or medical conditions.

Increased and uninhibited psychomotor activity in the presence of confusion is part of the continuum of cognitive emergence from acute TBI as described by the Rancho Los Amigos cognitive scale [16]. More recently, post-traumatic agitation has been defined as the state of aggression during the period of post-traumatic amnesia in the absence of other physical, medical or psychiatric causes, with a score of $\geq 21$ on the Agitated Behavior Scale (Figure 1) [17] [18]. This definition distinguishes post-traumatic agitation from psychomotor agitation that occurs later in recovery, and also recognizes that the majority of agitated or aggressive behavior resolves with cognitive clearing.

In acute care hospitals, treatment of agitation usually involves dopamine antagonists and sedatives, including benzodiazepines, or the use of opiates. TBI clinicians often avoid these medications due to concerns of potential inhibition of neuronal recovery [12]. Animal studies have suggested that typical dopamine antagonists, such as haloperidol, are associated with slower motor recoveries [19]. Human studies have demonstrated a longer period of post-traumatic amnesia for patients on first generation dopamine antagonists, though it has been suggested that this may be largely due to increased severity of injury [20]. Although these theoretical concerns exist, there is the clear reality that medications like dopamine antagonists are essential for safety of agitated TBI patients, particularly as they emerge from coma to further stages of activation and engagement.

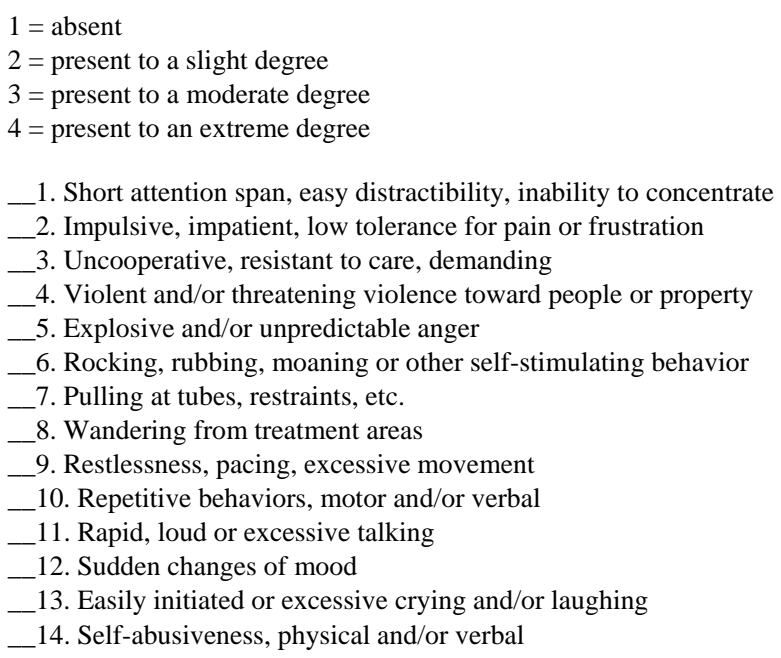

Figure 1. Agitated behavior scale [17]. 
AEDs have been considered reasonable options for the management of agitation after TBI [21]. There have been two small case studies and two case series evaluating the use of carbamazepine and valproic acid (VPA) in the acute period after injury. The effects of newer AEDs such as topiramate, lamotrigine, vigabatrin and tiagabine on agitation and aggression have not been studied in the TBI population and warrant further study.

Carbamazepine (CBZ) had been trialed for the treatment of TBI agitation in the acute setting given its quick onset of action and the fact that it has been shown to be effective for both alcohol withdrawal and mania [22] [23]. Chatham-Showalter looked at CBZ with a small $(N=7)$, non-controlled population of patients with TBI agitation in a trauma center. They found that within the window of two to four days of treatment onset there was a robust effect with respect to combativeness, impulsivity and distractibility, as compared to medications like haloperidol, morphine and benzodiazepines [8].

In a small retrospective analysis $(n=29)$ on the effectiveness of VPA on agitation in TBI, $28 \%(n=8)$ demonstrated dramatic improvement of symptoms, as assessed via the Agitated Behavior Scale, leading to discontinuation of other psychotropic medications completely. Eighteen patients (62\%) showed noticeably decreased agitation symptoms, but required ongoing benzodiazepines (2/18) or ongoing antipsychotics (4/18) for paranoia and delirium (i.e. sundowning). Moreover, 26 of 28 patients had a positive symptom response to divalproex [7].

Some practitioners are wary of the effect of AEDs on cognitive recovery after TBI; there are few studies to support or refute this claim [24]. Whereas the use of phenytoin in one study was associated with cognitive impairment, valproic acid and carbamazepine, when used as seizure prophylaxis, have not been shown to be associated with cognitive impairment [25]-[27]. Topiramate in patients with epilepsy and intellectual impairment was reported to cause language, attention, memory and executive function difficulties, and therefore practitioners may choose to avoid using this medication in the acute and post-acute TBI population [28] [29]. Gabapentin led to heightened anxiety and psychomotor agitation in 2 patients with traumatic brain injury [30]. Levetiracetam has also been shown to have neuropsychiatric effects such as aggression and loss of self-control, as well as increased activation and vigilance in the epilepsy population [31].

\subsection{Other Uses of AEDs in the Acute TBI Population}

Baguley and colleagues have studied the use of gabapentin in dysautonomia following acute TBI, demonstrating decreased dysautonomic paroxysms with additional beneficial effects with respect to pain and spasticity [32]. Dystonic posturing, as seen commonly in severe acute TBI, was also improved with titration of gabapentin. The authors hypothesized that the effects that were observed (decreasing of posturing and dysautonomia) were the result of attenuation of the afferent aspect of the abnormal response, rather than other classic models of attenuation focusing on the efferent aspect of dysregulation [32].

Finally, there remains ongoing research in the role of AEDs and neuroprotection. Animal models have suggested that antiepileptic medications may block downstream cascades of neuronal cell death after experimental brain injury, reducing functional impact and lesion size, though human clinical trials have not been successful to date [33]. Research in this area of neuroprotection and antiepileptic medications bears more attention, and the authors remain hopeful for the possibilities of future therapeutics during both acute and post-acute periods following TBI.

\section{Antiepileptic Drugs and Pain}

Effective use of medicine in patients with chronic pain is based on the evaluation of four main components of the pain complaint: nociceptive pain, CNS mechanisms of pain, suffering, and pain behavior [34]. The management of these four components utilizes opioids, anticonvulsants, antidepressants, and behavioral treatment. The World Health Organization (WHO) has established a three-step guideline for pain treatment. Step 1 involves the use of nonsteroidal anti-inflammatory drugs (NSAIDs), aspirin, or acetaminophen. Step 2 adds codeine to the NSAID, with other adjuvants (e.g., tricyclic antidepressants, other types of antidepressants, AEDs, and stimulants). Step 3 employs narcotics with adjunctive medication. Originally designed for the treatment of cancer pain, and efficacy reported in $90 \%$ of cancer patients, the three steps may be a useful template for many kinds of acute pain, adjusted for the particular pain mechanism being treated.

AEDs have a long history in the treatment of pain, especially neuropathic in origin, dating back to case reports for the treatment of trigeminal neuralgia with phenytoin in 1942 and carbamazepine in 1962 [35]. The proposed mechanisms for the efficacy of anticonvulsants with regard to treating pain are thought to include 
blocking abnormally high-frequency and spontaneous firing in afferent neurons in the dorsal horn and in the thalamus. The consequence of blocking the hyperexcitability of low-threshold mechanoreceptive neurons in the brain may lead to pain relief [36].

\subsection{Phenytoin}

Phenytoin has been shown effective in alleviating pain associated with various neuropathies, particularly trigeminal, diabetic, and post-stroke pain [37]. Symptoms of sharp, shooting, lancinating pain have been shown to respond especially well to this drug. It has a narrow therapeutic index with higher likelihood of drug toxicity and is less effective than carbamazepine in regards to analgesia.

\subsection{Carbamazepine}

Carbamazepine is generally more effective than phenytoin for pain. The effect of carbamazepine on pain suppression is likely mediated by central and peripheral mechanisms. The ability of carbamazepine to block ionic conductance appears to be frequency-dependent, which enables the drug to suppress the spontaneously active $\mathrm{A} \delta$ and $\mathrm{C}$ fibers responsible for pain without affecting normal nerve conduction. Since Blom reported the analgesic properties of carbamazepine for patients with trigeminal neuralgia in 1962, carbamazepine has been shown to be effective also for, post-herpetic pain, post-sympathetic pain, diabetic neuropathy, multiple sclerosis, and assorted neuralgias [38]. Higher levels (8 to $12 \mu \mathrm{g} / \mathrm{L}$ ) are typically necessary for optimal efficacy.

\subsection{Valproic Acid}

The first reports of VPA used in neuropathic pain appeared in the early 1980s [34]. VPA prolongs the repolarization of voltage activated $\mathrm{Na}^{+}$channels, and also increases the amount of GABA in the brain, enhancing the activity of glutamic acid decarboyxlase and inhibiting GABA degradation enzymes. VPA has been shown to decrease post-herpetic neuralgia, episodic and chronic cluster headaches, migraine, and post-operative pain, as well as various neuralgias. It has also been demonstrated that VPA is effective in treating migraine headaches in two double-blind, placebo-controlled trials [39] [40]. These demonstrations of efficacy in pain reduction are in addition to the traditional place for VPA in the treatment of psychiatric disorders (bipolar and schizoaffective disorders). VPA sprinkles, in particular, are well tolerated and can substitute for carbamazepine and lithium in pain states, although no head-to-head comparisons have been completed.

\subsection{Gabapentin}

Of the new generation of AEDs used for treatment of neuropathic pain, gabapentin is perhaps the best studied. Developed as a structural GABA analogue, it has no direct GABAergic action. It is believed that gabapentin acts on the $\alpha-2-\delta$ type of $\mathrm{Ca}^{2+}$ channels. Gabapentin has relieved pain and associated symptoms in patients with both peripheral diabetic neuropathy, post-herpetic neuralgia, HIV-related neuropathy, and cancer-related neuropathic pain [41]-[44]. The dosages used in these studies typically ranged from 900 - $3600 \mathrm{mg}$ daily in 3 divided doses. Additional studies are required to evaluate if gabapentin is efficacious in other pain states.

\subsection{Topiramate}

Topiramate works via multiple mechanisms (including prolongation of voltage-sensitive sodium channel inactivation, $\mathrm{GABA}_{\mathrm{A}}$ agonism, and non-N-methyl-D aspartate glutamate receptor antagonism). Topiramate is useful in the treatment of trigeminal neuralgia, along with diabetic neuropathy. Like any of the newer AEDs, continued studies will be required to determine overall efficacy.

\subsection{Oxcarbazepine}

Oxcarbazepine is a keto-analogue of carbamazepine, with the analgesic mechanism likely due to inhibition of voltage-dependent $\mathrm{Na}^{+}$channels and also, to a lesser extent, $\mathrm{K}^{+}$channels. While studies seem to show mixed results for the use of oxcarbazepine for diabetic neuropathy, it seems to have similar efficacy to carbamazepine in the treatment of trigeminal neuralgia; however, there is limited data regarding the efficacy and safety of this drug in the treatment of other neuropathic pain syndromes. 


\subsection{Pregabalin}

Pregabalin is a GABA analogue believed to exert its analgesic effect by binding to the $\alpha 2$ delta subunit of voltage-gated calcium channels on primary afferent nerves, and reducing the release of neurotransmitters from their central terminals. Evidence seems to show that pregabalin is effective for reducing the intensity of pain associated with diabetic polyneuropathy and post-herpetic neuralgia [45] [46].

\subsection{Lamotrigine}

Lamotrigine is a direct glutamate antagonist that also inhibits sodium channels. While initial case reports seemed to show some promise for use of lamotrigine in neuropathic pain states, most randomized, double-blind studies to date have not shown any significant efficacy [47]-[51].

\section{Antiepileptic Drugs and Alcohol Withdrawal}

Long-term exposure to ethanol results in several adaptive changes in neurotrotransmitter systems, including gamma-aninobutyric acid (GABA) receptors, glutamate receptors, and in noradrenergic activity [52]. Glutamate represents the most common excitatory neurotransmitter in the human brain and acts on several types of receptors in the central nervous system (CNS) of which, the $N$-methyl-D-aspartate (NMDA) receptor is the most effected [53]. In addition, recent evidence shows that other ionotropic glutamate receptors may be involved in the pathophysiology of alcohol withdrawal syndrome (AWS), including the $\alpha$-amino-3-hydroxy-5-methylisoxazole-4-propionic acid (AMPA) and the kainate subtypes of glutamate receptors [54] [55]. GABA is the major inhibitory neurotransmitter and binds to a fast-acting receptor complex GABA-A, which hyperpolarizes the cell membrane and inhibits neuroactivity [53]. Chronic exposure to ethanol results in neuroadaptive changes, including reduced GABA activity and increased glutamatergic action [56]. The "kindling phenomenon" has been suggested to describe worsening of withdrawal symptoms (particularly seizures) due to repeated cycles of chronic alcohol exposure and withdrawal [57] [58]. Kindling refers to long-term neuronal changes that occur resulting from repeated cycles of chronic alcohol exposure and withdrawal [58] [59]. Studies, in both animal and human experiments, show that the incidence and severity of alcohol withdrawal related seizures increases with the number of withdrawal events [60].

Currently, benzodiazepines are the medications of choice in the treatment of AWS [61] [62]. They have demonstrated efficacy in ameliorating symptoms and decreasing the risk of seizures and alcohol withdrawal delirium (AWD) [63]. Their use however has certain limitations, including the possibility of abuse, sedation, respiratory compromise, cognitive impairment and delirium. Over the last few years, recent studies suggest that AEDs may provide safe and effective alternatives to benzodiazepines, especially among patients with mild to moderate alcohol withdrawal symptoms. These agents have both anxiolytic and mood stabilizing effects along with their anticonvulsant activity and although their mechanism of action is not completely understood, the efficacy of AEDs in alcohol withdrawal is thought to be related to their ability to inhibit kindling and to facilitate GABA inhibitory neurotransmission [64].

\subsection{Carbamazepine}

Carbamazepine is the oldest AED medication investigated in the treatment of AWS, and is approved as a form of treatment for AWS in Germany [65]. A tricyclic anticonvulsant, carbamazepine inhibits voltage dependent sodium channels and activates the voltage-dependent potassium channels [66]. It has been found to suppress withdrawal-induced kindling in limbic structures [67] [68], and animal studies have also shown that carbamazepine is able to prevent alcohol withdrawal seizures [69] in addition to decreasing withdrawal symptoms [70].

Several double-blind studies have demonstrated that carbamazepine has equal or greater efficacy to lorazepam, oxazepam, clomethiazole, tiapride, or placebo in reducing withdrawal symptoms [67] [71]. In a study conducted by Malcolm and colleagues [71], 136 patients participated in a double-blind trial comparing carbamazepine versus lorazepam for the treatment of alcohol withdrawal detoxification. Subjects were stratified into two groups based on the number of past medical detoxifications, with one group including patients with none or one previous AWS episodes, and the other group including patients with multiple $(>1)$ previous AWS episodes. Subjects were randomized to five days of fixed dose taper of carbamazepine (starting at $600-800 \mathrm{mg} /$ day) or lorazepam (starting at 6 - $8 \mathrm{mg} /$ day). The CIWA-Ar [72] was administered to patients daily for five days during the 
treatment phase, as well as on days 7 and 12 of the post-treatment period. The results demonstrated that carbamazepine and lorazepam were equally effective in decreasing the acute symptoms of withdrawal. There were no significant differences by treatment group in CIWA-Ar scores when all 12 study days were evaluated, however a significant treatment group effect on post-treatment drinks per day was observed. Among patients with multiple detoxifications, those who received carbamazepine drank an average of $<1$ drink/day compared with about 5 drinks/day among the lorazepam group $(\mathrm{P}=0.004)$ [71].

\subsection{Valproic Acid}

Valproic acid is approved in the US for use in epilepsy and bipolar mood disorder [65]. VPA has both anticonvulsant and anti-kindling properties, and acts to enhance levels of GABA suppressing glutamate function via NMDA receptors [73] [74].

Two double blind comparative studies have been performed investigating VPA in the treatment of AWS. Reoux and colleages [75] performed a 7 day double-blind, placebo-controlled trial of VPA (500 mg three times daily) in acute AWS inpatients. The trial also included a baseline dose of oxazepam $30 \mathrm{mg}$ and additional oxazepam administration (in $30 \mathrm{mg}$ doses) as a rescue medication depending on the severity of withdrawal symptoms. The results demonstrated that patients treated with VPA needed less oxazepam and showed less progression in the severity of withdrawal symptoms (increase in CIWA-Ar above baseline) with respect to the placebo group. In addition, Hillbom and colleagues [76] conducted a double blind study in 138 patients who were randomized to receive VPA (1200 mg daily), carbamazepine (1200 mg daily), or placebo for four days. Seizures occurred in three subjects receiving placebo, two on carbamazepine and one on VPA. AWD developed in two patients receiving VPA and one receiving placebo [76].

\subsection{Phenobarbital}

Phenobarbital is the most commonly used AED used worldwide (Kwan et al.) to treat seizures, and also has sedative and hypnotic properties. The principal mechanism of action of phenobarbital is its affinity for the $\mathrm{GABA}_{\mathrm{A}}$ receptor. Barbiturates, such as phenobarbital, bind to the $\mathrm{GABA}_{\mathrm{A}}$ receptor at the alpha subunit, which are binding sites distinct from GABA itself and also at a different site from the benzodiazepine binding site. In addition to this GABAergic effect however, barbiturates also block the AMPA receptor, a subtype of glutamate receptor [77]. This anti-glutamatergic property may perhaps explain its efficacy in complicated alcohol withdrawal states.

Ives and colleagues have described an alcohol withdrawal protocol for outpatient detox in over 70 patients, based on the pharmacokinetic properties of phenobarbital [78]. The authors utilized intramuscular administration of phenobarbital initially to achieve a therapeutic serum level quickly, then switched to an orally administered taper over the following 6 days. Haloperidol and lorazepam were available for breakthrough agitation and withdrawal symptoms if needed, however were reportedly seldom used or needed [78]. In a prospective randomized double blind placebo controlled study, a single dose of intravenous phenobarbital $(10 \mathrm{mg} / \mathrm{kg}$ in $100 \mathrm{~mL}$ of normal saline) or placebo was administered. All patients were treated using an institutional symptom guided lorazepam-based alcohol withdrawal protocol. Patients administered phenobarbital were found to have decreased ICU admission, decreased amount of lorazepam administration, and did not have increased adverse outcomes [79]. Additional studies looking into the use of phenobarbital for both prophylaxis and treatment of active symptoms of alcohol withdrawal in the general hospital setting are actively ongoing.

\subsection{Gabapentin}

Gabapentin has FDA indication as an adjunctive form of treatment for partial seizures. Structurally related to GABA, it crosses the blood-brain barrier and readily distributes throughout the CNS.

Evidence supporting the potential role of gabapentin to reduce symptoms of AWS comes from case reports and several case series [80]-[85]. Rustembegovic and colleagues [86] have also described a case series in which there was a reduction in tonic-clonic seizures in a subset of patients with severe AWS. In a double blind trial of gabapentin versus lorazepam for the treatment of AWS, Myrick and Colleagues [87] found that the administration of gabapentin (1200 mg/day) was as effective as lorazepam for AWS as measured by CIWA-Ar, and that patients receiving gabapentin had reduced alcohol consumption in the immediate post-withdrawal week com- 
pared to lorazepam. An open trial of gabapentin in acute alcohol withdrawal used an oral loading protocol in 37 patients with a history of severe alcohol withdrawal symptoms [88]. In patients with severe alcohol withdrawal symptoms, as measured by the CIWA-Ar, were given gabapentin as an $800 \mathrm{mg}$ test dose, and depending on the clinical response titrated up to $3200 \mathrm{mg}$ in the first 24 hours. The authors concluded that the use of gabapentin with an $800 \mathrm{mg}$ initial load with subsequent titration was helpful in reducing less severe and less complicated acute AWS [88].

\section{Discussion}

Antiepileptic drugs are a broad class of medications with a spectrum of applications useful to the treatment of acute neuropsychiatric syndromes in the general hospital. Alteration of the hyper-excitability of low-threshold mechanoreceptive neurons in the brain modulates pain relief. The distinct quality and character of the pain experience is useful in guiding specific choices of AED as adjuvant therapies for neuropathies and headache with gabapentin, carbamazepine, and valproic acid, being the most studied. Traumatic brain injury constitutes a syndrome with presentations of seizures and neuropsychiatric symptoms. Having historically been utilized for the treatment of epilepsy, prophylaxis of early seizures in TBI with phenytoin is recommended; levetiracetam is increasing in use due to ease of dosing, though with unclear clinical benefit. Agitation is a common symptom of many disease states, including TBI and alcohol withdrawal. Carbamazepine and valproic acid have demonstrated effectiveness in reducing agitation and combativeness in TBI with the added benefit of conveying seizure prophylaxis. Similarly, in the treatment of alcohol withdrawal, AED offer an alternative or adjuvant to benzodiazepines, by facilitating inhibitory GABAergic neuronal activity (Table 1).

\section{Conclusion}

Utilization of AEDs in the acute care setting to target behavioral, affective and cognitive symptoms is steadily increasing. The choice of specific agents is generally limited by the side-effect profile, relative toxicity related to the primary medical condition, and ease of dosing and monitoring. As we learn more about the specific mechan-

Table 1. Antiepileptic medications frequently used in the general hospital.

\begin{tabular}{|c|c|c|c|}
\hline Name & Mechanism & Dosage & Side Effects \\
\hline Phenytoin & $\begin{array}{l}\text { Voltage gated sodium } \\
\text { channel blockade }\end{array}$ & $\begin{array}{l}\text { Titrate to serum level: } \\
15 \text { - } 20 \mathrm{mg} / \mathrm{dL} \text {; } \\
\text { Max dose } 625 \mathrm{mg} / \text { day. }\end{array}$ & $\begin{array}{l}\text { Cognitive deficits, nstagmus, ataxia, seizures, } \\
\text { opthalmoparesis, sedation, anemia, gingival } \\
\text { hyperplasia, allergy, drug induced lupus }\end{array}$ \\
\hline Levetiracetam & $\begin{array}{l}\text { Binding to SV2A } \\
\text { (synaptic vesicle protein) }\end{array}$ & $\begin{array}{l}500 \mathrm{mg} \text { BID to max daily } \\
\text { dose of } 3000 \mathrm{mg} / \text { day }\end{array}$ & $\begin{array}{l}\text { Hair loss, dysesthesias, anxiety, irritability, } \\
\text { depression, headache, nausea, sedation, weakness }\end{array}$ \\
\hline Valproic acid & $\begin{array}{l}\text { Voltage gated sodium } \\
\text { channel blockade }\end{array}$ & $\begin{array}{l}750 \text { - } 2250 \mathrm{mg} / \text { day (once a } \\
\text { day dosing to QID dosing); } \\
\text { target serum level of } \\
75-100 \mathrm{mg} / \mathrm{dL}\end{array}$ & $\begin{array}{l}\text { Hepatic failure, pancreatitis, somnolence, } \\
\text { thrombocytopenia, hypothermia, hyperammonemia, } \\
\text { encephalopathy, multiorgan hypersensitivity } \\
\text { reaction, depressed cognition. }\end{array}$ \\
\hline Carbamazepine & $\begin{array}{l}\text { Voltage gated sodium } \\
\text { channel blockade }\end{array}$ & $\begin{array}{l}400 \text { - } 800 \mathrm{mg} / \text { day (BID to } \\
\text { QID dosage); target serum } \\
\text { level of } 7 \text { - } 10 \mathrm{mg} / \mathrm{dL}\end{array}$ & $\begin{array}{l}\text { Hyperammonemia Toxic epidermal necrolysis, } \\
\text { Stevens-Johnson Syndrome, aplastic anemia, } \\
\text { agranulocytosis, heart block, multiorgan } \\
\text { hypersensitivity reaction, anticholinergic effects, } \\
\text { psychosis, renal dysfunction, visual problems, } \\
\text { hyponatremia, hypothyroidism }\end{array}$ \\
\hline Lamotrigine & $\begin{array}{l}\text { Unknown, sodium channel } \\
\text { blockade }\end{array}$ & $\begin{array}{l}\text { Initial starting dose of } \\
50 \mathrm{mg} / \text { day (slow titration } \\
\text { upwards in dose required) }\end{array}$ & $\begin{array}{l}\text { SJS, TENS, headache, dizziness, insomnia, } \\
\text { myalgias, dry mouth, irritability, fatigue, } \\
\text { memory and cognitive difficulty }\end{array}$ \\
\hline Gabapentin & $\begin{array}{l}\text { Voltage gated calcium } \\
\text { channel inhibition }\end{array}$ & 300 - 3600 mg TID & $\begin{array}{l}\text { Anxiety, psychomotor agitation, peripheral } \\
\text { edema, dizziness, sedation, hepatotoxicity }\end{array}$ \\
\hline Topiramate & $\begin{array}{l}\text { Unclear mechanism, inhibits } \\
\text { depolarization invoked } \\
\text { sustained repetitive firing } \\
\text { in } \mathrm{Na} / \mathrm{Ca} \text { channels }\end{array}$ & $\begin{array}{l}25 \text { mg daily with titration } \\
\text { upwards to } 200 \mathrm{mg} \text { BID }\end{array}$ & $\begin{array}{l}\text { Impairment of language, attention, memory, } \\
\text { executive functioning }\end{array}$ \\
\hline
\end{tabular}


isms of action of newer AEDs, we will have newer approaches to treat a variety of conditions related to abnormal neuronal activity and reactivity. What the $20^{\text {th }}$ century was for the treatment of epilepsy with AEDs, the $21^{\text {st }}$ century holds promise for the expanded treatment of additional acute neuropsychiatric conditions.

\section{References}

[1] Rho, J.M. and Sankar, R. (1999) The Pharmacologic Basis of Antiepileptic Drug Action. Epilepsia, 40, $1471-1483$. http://dx.doi.org/10.1111/j.1528-1157.1999.tb02029.x

[2] Shorvon, S.D. (2009) Drug Treatment of Epilepsy in the Century of the ILAE: The First 50 Years, 1909-1958. Epilepsia, 50, 69-92. http://dx.doi.org/10.1111/j.1528-1167.2009.02041.x

[3] Armijo, J.A., Adin, J. and Sanchez, M.B. (2006) Mecanismo de acción de los antiepilépticos y nuevos antiepilépticos. Revue Neurologique, 43, S17-S41.

[4] Chouinard, G. (2006) The Search for New Off-Label Indications for Antidepressant, Antianxiety, Antipsychotic and Anticonvulsant Drugs. Journal of Psychiatry and Neuroscience, 31, 168-176.

[5] Langlois, J.A., Rutland-Brown, W. and Wald, M.M. (2006) The Epidemiology and Impact of Traumatic Brain Injury: A Brief Overview. The Journal of Head Trauma Rehabilitation, 21, 375-378. http://dx.doi.org/10.1097/00001199-200609000-00001

[6] Yasseen, B., Colantonio, A. and Ratcliff, G. (2008) Prescription Medication Use in Persons Many Years Following Traumatic Brain Injury. Brain Injury, 22, 752-757. http://dx.doi.org/10.1080/02699050802320132

[7] Chatham Showalter, P.E. and Kimmel, D.N. (2000) Agitated Symptom Response to Divalproex Following Acute Brain Injury. The Journal of Neuropsychiatry \& Clinical Neurosciences, 12, 395-397. http://dx.doi.org/10.1176/appi.neuropsych.12.3.395

[8] Chatham-Showalter, P.E. (1996) Carbamazepine for Combativeness in Acute Traumatic Brain Injury. The Journal of Neuropsychiatry \& Clinical Neurosciences, 8, 96-99. http://dx.doi.org/10.1046/j.1528-1157.44.s10.4.X

[9] Schierhout, G. and Roberts, I. (2012) Antiepileptic Drugs for Preventing Seizures Following Acute Traumatic Brain Injury. Cochrane Database of Systematic Reviews, 2012, Article ID: CD000173.

[10] Frey, L.C. (2003) Epidemiology of Posttraumatic Epilepsy: A Critical Review. Epilepsia, 44, 11-17.

[11] Lowenstein, D.H. (2009) Epilepsy after Head Injury: An Overview. Epilepsia, 50, 4-9. http://dx.doi.org/10.1111/j.1528-1167.2008.02004.x

[12] Fugate, L.P., Spacek, L.A., Kresty, L.A., Levy, C.E., Johnson, J.C. and Mysiw, W.J. (1997) Measurement and Treatment of Agitation Following Traumatic Brain Injury: II. A Survey of the Brain Injury Special Interest Group of the American Academy of Physical Medicine and Rehabilitation. Archives of Physical Medicine and Rehabilitation, 78, 924-928. http://dx.doi.org/10.1016/S0003-9993(97)90051-4

[13] Jones, K.E., Puccio, A.M., Harshman, K.J., Falcione, B., Benedict, N., Jankowitz, B.T., Stippler, M., Fischer, M., Sauber-Schatz, E.K., Fabio, A., Darby, J.M. and Okonkwo, D.O. (2008) Levetiracetam versus Phenytoin for Seizure Prophylaxis in Severe Traumatic Brain Injury. Neurosurgical Focus, 25, E3.

http://dx.doi.org/10.3171/FOC.2008.25.10.E3

[14] Fugate, L.P., Spacek, L.A., Kresty, L.A., Levy, C.E., Johnson, J.C. and Mysiw, W.J. (1997) Definition of Agitation Following Traumatic Brain Injury: I. A Survey of the Brain Injury Special Interest Group of the American Academy of Physical Medicine and Rehabilitation. Archives of Physical Medicine and Rehabilitation, 78, 917-923. http://dx.doi.org/10.1016/S0003-9993(97)90050-2

[15] (1989) Oxford English Dictionary. 2nd Edition, Oxford University Press, Oxford.

[16] Hagen, C., Malcmus, D. and Durham, P. (1979) Rehabilitation of the Head of Injured Adult: Comprehensive Physical Management. Professional Staff Association of Rancho Los Amigos Hospital, Downey, 87-89.

[17] Lombard, L.A. and Zafonte, R.D. (2005) Agitation after Traumatic Brain Injury: Considerations and Treatment Options. American Journal of Physical Medicine \& Rehabilitation, 84, 797-812. http://dx.doi.org/10.1097/01.phm.0000179438.22235.08

[18] Sandel, M.E. and Mysiw, W.J. (1996) The Agitated Brain Injured Patient. Part 1: Definitions, Differential Diagnosis, and Assessment. Archives of Physical Medicine and Rehabilitation, 77, 617-623. http://dx.doi.org/10.1016/S0003-9993(96)90306-8

[19] Wilson, M.S., Gibson, C.J. and Hamm, R.J. (2003) Haloperidol, but Not Olanzapine, Impairs Cognitive Performance after Traumatic Brain Injury in Rats. American Journal of Physical Medicine \& Rehabilitation, 82, 871-879. http://dx.doi.org/10.1097/01.PHM.0000091982.33232.CB

[20] Rao, N., Jellinek, H.M. and Woolston, D.C. (1985) Agitation in Closed Head Injury: Haloperidol Effects on Rehabilitation Outcome. Archives of Physical Medicine and Rehabilitation, 66, 30-34. 
[21] Persinger, M.A. (2000) Subjective Improvement Following Treatment with Carbamazepine (Tegretol) for a Subpopulation of Patients with Traumatic Brain Injuries. Perceptual and Motor Skills, 90, 37-40. http://dx.doi.org/10.2466/pms.2000.90.1.37

[22] Stuppaeck, C.H., Pycha, R., Miller, C., Whitworth, A.B., Oberbauer, H. and Fleischhacker, W.W. (1992) Carbamazepine versus Oxazepam in the Treatment of Alcohol Withdrawal: A Double-Blind Study. Alcohol and Alcoholism, 27, 153-158.

[23] Small, J.G., Klapper, M.H., Milstein, V., Kellams, J.J., Miller, M.J., Marhenke, J.D. and Small, I.F. (1991) Carbamazepine Compared with Lithium in the Treatment of Mania. JAMA Psychiatry, 48, 915-921. http://dx.doi.org/10.1001/archpsyc.1991.01810340047006

[24] Massagli, T.L. (1991) Neurobehavioral Effects of Phenytoin, Carbamazepine, and Valproic Acid: Implications for Use in Traumatic Brain Injury. Archives of Physical Medicine and Rehabilitation, 72, 219-226.

[25] Dikmen, S.S., Machamer, J.E., Winn, H.R., Anderson, G.D. and Temkin, N.R. (2000) Neuropsychological Effects of Valproate in Traumatic Brain Injury: A Randomized Trial. Neurology, 54, 895-902. http://dx.doi.org/10.1212/WNL.54.4.895

[26] Smith Jr., K.R., Goulding, P.M., Wilderman, D., Goldfader, P.R., Holterman-Hommes, P. and Wei, F.F. (1994) Neurobehavioral Effects of Phenytoin and Carbamazepine in Patients Recovering from Brain Trauma: A Comparative Study. JAMA Neurology, 51, 653-660. http://dx.doi.org/10.1001/archneur.1994.00540190029012

[27] Azouvi, P., Jokic, C., Attal, N., Denys, P., Markabi, S. and Bussel, B. (1999) Carbamazepine in Agitation and Aggressive Behaviour Following Severe Closed-Head Injury: Results of an Open Trial. Brain Injury, 13, 797-804. http://dx.doi.org/10.1080/026990599121188

[28] Tang, V., Warden, J., Cullen, N. and Rutledge, E. (2007) Topiramate in Traumatic Brain Injury: Adverse Effects on Cognitive Function. Journal of Head Trauma Rehabilitation, 22, 409-410. http://dx.doi.org/10.1097/01.HTR.0000300236.21114.bc

[29] Lee, H.W., Jung, D.K., Suh, C.K., Kwon, S.H. and Park, S.P. (2006) Cognitive Effects of Low-Dose Topiramate Monotherapy in Epilepsy Patients: A 1-Year Follow-Up. Epilepsy \& Behavior, 8, 736-741. http://dx.doi.org/10.1016/j.yebeh.2006.03.006

[30] Childers, M.K. and Holland, D. (1997) Psychomotor Agitation Following Gabapentin Use in Brain Injury. Brain Injury, 11, 537-540. http://dx.doi.org/10.1080/713802187

[31] Helmstaedter, C., Fritz, N.E., Kockelmann, E., Kosanetzky, N. and Elger, C.E. (2008) Positive and Negative Psychotropic Effects of Levetiracetam. Epilepsy \& Behavior, 13, 535-541. http://dx.doi.org/10.1016/j.yebeh.2008.05.012

[32] Baguley, I.J., Heriseanu, R.E., Gurka, J.A., Nordenbo, A. and Cameron, I.D. (2007) Gabapentin in the Management of Dysautonomia Following Severe Traumatic Brain Injury: A Case Series. Journal of Neurology, Neurosurgery \& Psychiatry, 78, 539-541. http://dx.doi.org/10.1136/jnnp.2006.096388

[33] Willmore, L.J. (2005) Antiepileptic Drugs and Neuroprotection: Current Status and Future Roles. Epilepsy \& Behavior, 7, 25-28. http://dx.doi.org/10.1016/j.yebeh.2005.08.006

[34] Nejad, S. and Alpay, M. (2010) Pain Patients. In: Stern, T.A., Fricchione, G.L., Cassem, E.H., Jellinek, M. and Rosenbaum, J.F., Eds., MGH Handbook of General Hospital Psychiatry, Saunders, Washington D.C., 211-236. http://dx.doi.org/10.1016/B978-1-4377-1927-7.00018-2

[35] Blom, S. (1962) Trigeminal Neuralgia: Its Treatment with a New Anticonvulsant Drug (G-32883). Lancet, 279, 839-840. http://dx.doi.org/10.1016/S0140-6736(62)91847-0

[36] Rogawski, M.A. and Loscher, W. (2004) The Neurobiology of Antiepileptic Drugs for the Treatment of Nonepileptic Conditions. Nature Medicine, 10, 685-692. http://dx.doi.org/10.1038/nm1074

[37] Jensen, T.S. (2002) Anticonvulsants in Neuropathic Pain: Rationale and Clinical Evidence. European Journal of Pain, 6, 61-68.

[38] Maciewicz, R., Bouckoms, A. and Martin, J.B. (1985) Drug Therapy of Neuropathic Pain. Clinical Journal of Pain, 1, 39-45. http://dx.doi.org/10.1097/00002508-198501010-00006

[39] Hering, R. and Kuritzky, A. (1989) Sodium Valproate in the Treatment of Cluster Headache: An Open Clinical Trial. Cephalalgia, 9, 195-198. http://dx.doi.org/10.1046/j.1468-2982.1989.0903195.x

[40] Freitag, F.G., Collins, S.D., Carlson, H.A., Goldstein, J., Saper, J., Silberstein, S., Mathew, N., Winner, P.K., Deaton, R. and Sommerville, K. (2002) A Randomized Trial of Divalproex Sodium Extended-Release Tablets in Migraine Prophylaxis. Neurology, 58, 1652-1659. http://dx.doi.org/10.1212/WNL.58.11.1652

[41] Backonja, M., Beydoun, A., Edwards, K.R., Schwartz, S.L., Fonseca, V., Hes, M., LaMoreaux, L. and Garofalo, E. (1998) Gabapentin for the Symptomatic Treatment of Painful Neuropathy in Patients with Diabetes Mellitus: A Randomized Controlled Trial. JAMA, 280, 1831-1836. http://dx.doi.org/10.1001/jama.280.21.1831 
[42] Rowbotham, M., Harden, N., Stacey, B., Bernstein, P. and Magnus-Miller, L. (1998) Gabapentin for the Treatment of Postherpetic Neuralgia: A Randomized Controlled Trial. JAMA, 280, 1837-1842. http://dx.doi.org/10.1001/jama.280.21.1837

[43] Hahn, K., Arendt, G., Braun, J.S., von Giesen, H.J., Husstedt, I.W., Maschke, M., Straube, M.E. and Schielke, E. (2004) A Placebo-Controlled Trial of Gabapentin for Painful HIV-Associated Sensory Neuropathies. Journal of Neurology, 251, 1260-1266. http://dx.doi.org/10.1007/s00415-004-0529-6

[44] Caraceni, A., Zecca, E., Bonezzi, C., Arcuri, E., Yaya Tur, R., Maltoni, M., Visentin, M., Gorni, G., Martini, C., Tirelli, W., Barbieri, M. and De Conno, F. (2004) Gabapentin for Neuropathic Cancer Pain: A Randomized Controlled Trial from the Gabapentin Cancer Pain Study Group. Journal of Clinical Oncology, 22, 2909-2917. http://dx.doi.org/10.1200/JCO.2004.08.141

[45] Lesser, H., Sharma, U., LaMoreaux, L. and Poole, R.M. (2004) Pregabalin Relieves Symptoms of Painful Diabetic Neuropathy: A Randomized Controlled Trial. Neurology, 63, 2104-2110. http://dx.doi.org/10.1212/01.WNL.0000145767.36287.A1

[46] Sabatowski, R., Galvez, R., Cherry, D.A., Jacquot, F., Vincent, E., Maisonobe, P. and Versavel, M. (2004) Pregabalin Reduces Pain and Improves Sleep and Mood Disturbances in Patients with Post-Herpetic Neuralgia: Results of a Randomised, Placebo-Controlled Clinical Trial. Pain, 109, 26-35. http://dx.doi.org/10.1016/j.pain.2004.01.001

[47] Vinik, A.I., Tuchman, M., Safirstein, B., Corder, C., Kirby, L., Wilks, K., Quessy, S., Blum, D., Grainger, J., White, J. and Silver, M. (2007) Lamotrigine for Treatment of Pain Associated with Diabetic Neuropathy: Results of Two Randomized, Double-Blind, Placebo-Controlled Studies. Pain, 128, 169-179. http://dx.doi.org/10.1016/j.pain.2006.09.040

[48] Jose, V.M., Bhansali, A., Hota, D. and Pandhi, P. (2007) Randomized Double-Blind Study Comparing the Efficacy and Safety of Lamotrigine and Amitriptyline in Painful Diabetic Neuropathy. Diabetic Medicine, 24, 377-383. http://dx.doi.org/10.1111/j.1464-5491.2007.02093.x

[49] Silver, M., Blum, D., Grainger, J., Hammer, A.E. and Quessy, S. (2007) Double-Blind, Placebo-Controlled Trial of Lamotrigine in Combination with Other Medications for Neuropathic Pain. Journal of Pain and Symptom Management, 34, 446-454. http://dx.doi.org/10.1016/i.jpainsymman.2006.12.015

[50] Rao, R.D., Flynn, P.J., Sloan, J.A., Wong, G.Y., Novotny, P., Johnson, D.B., Gross, H.M., Renno, S.I., Nashawaty, M. and Loprinzi, C.L. (2008) Efficacy of Lamotrigine in the Management of Chemotherapy-Induced Peripheral Neuropathy. Cancer, 112, 2802-2808. http://dx.doi.org/10.1002/cncr.23482

[51] Wiffen, P.J. and Rees, J. (2007) Lamotrigine for Acute and Chronic Pain. Cochrane Database of Systematic Reviews, Article ID: CD006044.

[52] Addolorato, G., Leggio, L., Abenavoli, L. and Gasbarrini, G. (2005) Neurobiochemical and Clinical Aspects of Craving in Alcohol Addiction: A Review. Addictive Behaviors, 30, 1209-1224. http://dx.doi.org/10.1016/j.addbeh.2004.12.011

[53] Chastain, G. (2006) Alcohol, Neurotransmitter Systems, and Behavior. Journal of General Psychology, 133, $329-335$. http://dx.doi.org/10.3200/GENP.133.4.329-335

[54] Carta, M., Olivera, D.S., Dettmer, T.S. and Valenzuela, C.F. (2002) Ethanol Withdrawal Upregulates Kainate Receptors in Cultured Rat Hippocampal Neurons. Neuroscience Letters, 327, 128-132. http://dx.doi.org/10.1016/S0304-3940(02)00399-3

[55] Haugbol, S.R., Ebert, B. and Ulrichsen, J. (2005) Upregulation of Glutamate Receptor Subtypes during Alcohol Withdrawal in Rats. Alcohol and Alcoholism, 40, 89-95. http://dx.doi.org/10.1093/alcalc/agh117

[56] Littleton, J. (1998) Neurochemical Mechanisms Underlying Alcohol Withdrawal. Alcohol Health and Research World, 22, 13-24.

[57] Ballenger, J.C. and Post, R.M. (1978) Kindling as a Model for Alcohol Withdrawal Syndromes. British Journal of Psychiatry, 133, 1-14. http://dx.doi.org/10.1192/bjp.133.1.1

[58] Malcolm, R.J. (2003) GABA Systems, Benzodiazepines, and Substance Dependence. Journal of Clinical Psychiatry, 64, 36-40.

[59] Bayard, M., McIntyre, J., Hill, K.R. and Woodside Jr., J. (2004) Alcohol Withdrawal Syndrome. American Family Physician, 69, 1443-1450.

[60] Becker, H.C. and Littleton, J.M. (1996) The Alcohol Withdrawal "Kindling” Phenomenon: Clinical and Experimental Findings. Alcoholism: Clinical and Experimental Research, 20, 121a-124a. http://dx.doi.org/10.1111/j.1530-0277.1996.tb01760.x

[61] Saitz, R., Mayo-Smith, M.F., Roberts, M.S., Redmond, H.A., Bernard, D.R. and Calkins, D.R. (1994) Individualized Treatment for Alcohol Withdrawal: A Randomized Double-blind Controlled Trial. JAMA, 272, 519-523. http://dx.doi.org/10.1001/jama.1994.03520070039035 
[62] Mayo-Smith, M.F. (1997) Pharmacological Management of Alcohol Withdrawal: A Meta-Analysis and EvidenceBased Practice Guideline. JAMA, 278, 144-151. http://dx.doi.org/10.1001/jama.1997.03550020076042

[63] Saitz, R., Horton, N.J., Larson, M.J., Winter, M. and Samet, J.H. (2005) Primary Medical Care and Reductions in Addiction Severity: A Prospective Cohort Study. Addiction, 100, 70-78. http://dx.doi.org/10.1111/j.1360-0443.2005.00916.x

[64] Rogawski, M.A. (2005) Update on the Neurobiology of Alcohol Withdrawal Seizures. Epilepsy Currents, 5, 225-230. http://dx.doi.org/10.1111/j.1535-7511.2005.00071.x

[65] Leggio, L., Kenna, G.A. and Swift, R.M. (2008) New Developments for the Pharmacological Treatment of Alcohol Withdrawal Syndrome. A Focus on Non-Benzodiazepine GABAergic Medications. Progress in Neuro-Psychopharmacology and Biological Psychiatry, 32, 1106-1117. http://dx.doi.org/10.1016/j.pnpbp.2007.09.021

[66] Armijo, J.A., Shushtarian, M., Valdizan, E.M., Cuadrado, A., de las Cuevas, I. and Adin, J. (2005) Ion Channels and Epilepsy. Current Pharmaceutical Design, 11, 1975-2003. http://dx.doi.org/10.2174/1381612054021006

[67] Malcolm, R., Myrick, H., Brady, K.T. and Ballenger, J.C. (2001) Update on Anticonvulsants for the Treatment of Alcohol Withdrawal. American Journal on Addictions, 10, s16-s23. http://dx.doi.org/10.1080/10550490150504100

[68] Ait-Daoud, N., Malcolm Jr., R.J. and Johnson, B.A. (2006) An Overview of Medications for the Treatment of Alcohol Withdrawal and Alcohol Dependence with an Emphasis on the Use of Older and Newer Anticonvulsants. Addictive Behaviors, 31, 1628-1649. http://dx.doi.org/10.1016/j.addbeh.2005.12.029

[69] Chu, N.S. (1979) Carbamazepine: Prevention of Alcohol Withdrawal Seizures. Neurology, 29, 1397-1401. http://dx.doi.org/10.1212/WNL.29.10.1397

[70] Strzelec, J.S. and Czarnecka, E. (2001) Influence of Clonazepam and Carbamazepine on Alcohol Withdrawal Syndrome, Preference and Development of Tolerance to Ethanol in Rats. Polish Journal of Pharmacology, 53, 117-124.

[71] Malcolm, R., Myrick, H., Roberts, J., Wang, W., Anton, R.F. and Ballenger, J.C. (2002) The Effects of Carbamazepine and Lorazepam on Single versus Multiple Previous Alcohol Withdrawals in an Outpatient Randomized Trial. Journal of General Internal Medicine, 17, 349-355. http://dx.doi.org/10.1007/s11606-002-0038-1

[72] Sullivan, J.T., Sykora, K., Schneiderman, J., Naranjo, C.A. and Sellers, E.M. (1989) Assessment of Alcohol Withdrawal: The Revised Clinical Institute Withdrawal Assessment for Alcohol Scale (CIWA-Ar). British Journal of Addiction, 84, 1353-1357. http://dx.doi.org/10.1111/j.1360-0443.1989.tb00737.x

[73] Keck Jr., P.E., McElroy, S.L. and Friedman, L.M. (1992) Valproate and Carbamazepine in the Treatment of Panic and Posttraumatic Stress Disorders, Withdrawal States, and Behavioral Dyscontrol Syndromes. Journal of Clinical Psychopharmacology, 12, 36S-41S. http://dx.doi.org/10.1097/00004714-199202001-00006

[74] Loscher, W. (2002) Basic Pharmacology of Valproate. CNS Drugs, 16, 669-694. http://dx.doi.org/10.2165/00023210-200216100-00003

[75] Reoux, J.P., Saxon, A.J., Malte, C.A., Baer, J.S. and Sloan, K.L. (2001) Divalproex Sodium in Alcohol Withdrawal: A Randomized Double-Blind Placebo-Controlled Clinical Trial. Alcoholism: Clinical and Experimental Research, 25, 1324-1329. http://dx.doi.org/10.1111/j.1530-0277.2001.tb02354.x

[76] Hillbom, M., Tokola, R., Kuusela, V., Karkkainen, P., Kalli-Lemma, L., Pilke, A. and Kaste, M. (1989) Prevention of Alcohol Withdrawal Seizures with Carbamazepine and Valproic Acid. Alcohol, 6, 223-226. http://dx.doi.org/10.1016/0741-8329(89)90022-0

[77] Teichberg, V.I., Tal, N., Goldberg, O. and Luini, A. (1984) Barbiturates, Alcohols and the CNS Excitatory Neurotransmission: Specific Effects on the Kainate and Quisqualate Receptors. Brain Research, 291, 285-292. http://dx.doi.org/10.1016/0006-8993(84)91260-5

[78] Ives, T.J., Mooney, A.J. and Gwyther, R.E. (1991) Pharmacokinetic Dosing of Phenobarbital in the Treatment of Alcohol Withdrawal Syndrome. Southern Medical Journal, 84, 18-21. http://dx.doi.org/10.1097/00007611-199101000-00006

[79] Rosenson, J., Clements, C., Simon, B., Vieaux, J., Graffman, S., Vahidnia, F., Cisse, B., Lam, J. and Alter, H. (2013) Phenobarbital for Acute Alcohol Withdrawal: A Prospective Randomized Double-Blind Placebo-Controlled Study. The Journal of Emergency Medicine, 44, 592.e2-598.e2.

[80] Chatterjee, C.R. and Ringold, A.L. (1999) A Case Report of Reduction in Alcohol Craving and Protection against Alcohol Withdrawal by Gabapentin. Journal of Clinical Psychiatry, 60, 617. http://dx.doi.org/10.4088/JCP.v60n0911

[81] Bonnet, U., Banger, M., Leweke, F.M., Maschke, M., Kowalski, T. and Gastpar, M. (1999) Treatment of Alcohol Withdrawal Syndrome with Gabapentin. Pharmacopsychiatry, 32, 107-109. http://dx.doi.org/10.1055/s-2007-979203

[82] Bozikas, V., Petrikis, P., Gamvrula, K., Savvidou, I. and Karavatos, A. (2002) Treatment of Alcohol Withdrawal with Gabapentin. Progress in Neuro-Psychopharmacology and Biological Psychiatry, 26, 197-199. http://dx.doi.org/10.1016/S0278-5846(01)00234-2 
[83] Karam-Hage, M. and Brower, K.J. (2000) Gabapentin Treatment for Insomnia Associated with Alcohol Dependence. American Journal of Psychiatry, 157, 151.

[84] Myrick, H., Malcolm, R. and Brady, K.T. (1998) Gabapentin Treatment of Alcohol Withdrawal (Letter). American Journal of Psychiatry, 155, 1632.

[85] Voris, J., Smith, N.L., Rao, S.M., Thorne, D.L. and Flowers, Q.J. (2003) Gabapentin for the Treatment of Ethanol Withdrawal. Substance Abuse, 24, 129-132.

[86] Rustembegovic, A., Sofic, E., Tahirovic, I. and Kundurovic, Z. (2004) A Study of Gabapentin in the Treatment of Tonic-Clonic Seizures of Alcohol Withdrawal Syndrome. Medicinski Arhiv, 58, 5-6.

[87] Myrick, H., Malcolm, R., Randall, P.K., Boyle, E., Anton, R.F., Becker, H.C. and Randall, C.L. (2009) A DoubleBlind Trial of Gabapentin Versus Lorazepam in the Treatment of Alcohol Withdrawal. Alcoholism: Clinical and Experimental Research, 33, 1582-1588. http://dx.doi.org/10.1111/j.1530-0277.2009.00986.x

[88] Bonnet, U., Specka, M., Hamzavi Abedi, R., Wiltfang, J. and Scherbaum, N. (2009) Severe Protracted Alcohol Withdrawal Syndrome: Prevalence and Pharmacological Treatment at an Inpatient Detoxification Unit-A Naturalistic Study. Pharmacopsychiatry, 42, 76-78. http://dx.doi.org/10.1055/s-0028-1103292 
Scientific Research Publishing (SCIRP) is one of the largest Open Access journal publishers. It is currently publishing more than 200 open access, online, peer-reviewed journals covering a wide range of academic disciplines. SCIRP serves the worldwide academic communities and contributes to the progress and application of science with its publication.

Other selected journals from SCIRP are listed as below. Submit your manuscript to us via either submit@scirp.org or Online Submission Portal.
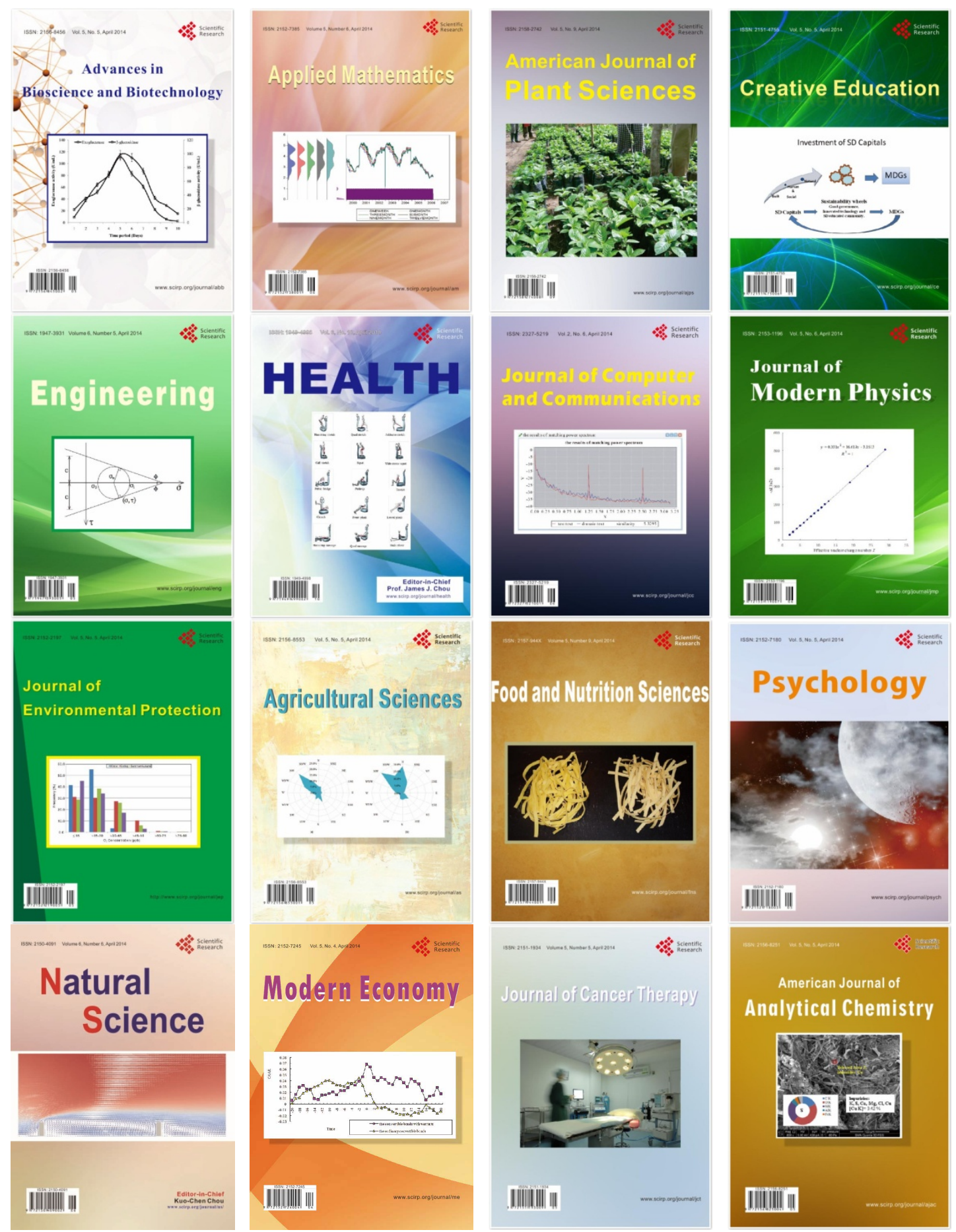